\title{
Tinnitus Does Not Interfere with Auditory and Speech Perception
}

\author{
${ }^{-}$Fan-Gang Zeng, Matthew Richardson, and Katie Turner \\ Center for Hearing Research, Departments of Anatomy and Neurobiology, Biomedical Engineering, Cognitive Sciences, Otolaryngology-Head and \\ Neck Surgery, University of California Irvine, Irvine, California 92697
}

Tinnitus is a sound heard by $15 \%$ of the general population in the absence of any external sound. Because external sounds can sometimes mask tinnitus, tinnitus is assumed to affect the perception of external sounds, leading to hypotheses such as "tinnitus filling in the temporal gap" in animal models and "tinnitus inducing hearing difficulty" in human subjects. Here we compared performance in temporal, spectral, intensive, masking and speech-in-noise perception tasks between 45 human listeners with chronic tinnitus (18 females and 27 males with a range of ages and degrees of hearing loss) and 27 young, normal-hearing listeners without tinnitus (11 females and 16 males). After controlling for age, hearing loss, and stimulus variables, we discovered that, contradictory to the widely held assumption, tinnitus does not interfere with the perception of external sounds in 32 of the 36 measures. We interpret the present result to reflect a bottom-up pathway for the external sound and a separate top-down pathway for tinnitus. We propose that these two perceptual pathways can be independently modulated by attention, which leads to the asymmetrical interaction between external and internal sounds, and several other puzzling tinnitus phenomena such as discrepancy in loudness between tinnitus rating and matching. The present results suggest not only a need for new theories involving attention and central noise in animal tinnitus models but also a shift in focus from treating tinnitus to managing its comorbid conditions when addressing complaints about hearing difficulty in individuals with tinnitus.

Key words: animal model; attention; auditory perception; neural noise; speech recognition; tinnitus

\section{Significance Statement}

Tinnitus, or ringing in the ears, is a neurologic disorder that affects $15 \%$ of the general population. Here we discovered an asymmetrical relationship between tinnitus and external sounds: although external sounds have been widely used to cover up tinnitus, tinnitus does not impair, and sometimes even improves, the perception of external sounds. This counterintuitive discovery contradicts the general belief held by scientists, clinicians, and even individuals with tinnitus themselves, who often report hearing difficulty, especially in noise. We attribute the counterintuitive discovery to two independent pathways: the bottom-up perception of external sounds and the top-down perception of tinnitus. Clinically, the present work suggests a shift in focus from treating tinnitus itself to treating its comorbid conditions and secondary effects.

Received Feb. 18, 2020; revised May 31, 2020; accepted June 12, 2020.

Author contributions: F.-G.Z., M.R., and K.T. designed research; F.-G.Z., M.R., and K.T. performed research;

F.-G.Z., M.R., and K.T. analyzed data; F.-G.Z. wrote the paper.

F.-G.Z. owns stock in Axonics, Nurotron, Syntiant, and Velox Biosystems. The authors declare no other competing financial interests.

This work was supported in part by National Institutes of Health Grant 5R01-DC-015587. We thank Hengji Chen for help with data collection in the overshoot experiment, and Omid Moshtaghi and Neil Saez for help with data collection in the temporal modulation and speech perception experiments. We also thank John Middlebrooks, Michelle Kapolowicz, Matthew Suh, Phillip Tran, Ruth Anne Eatock, Dan Sanes, and Brian C.J.

Moore and an anonymous reviewer for comments on the manuscript.

Correspondence should be addressed to Fan-Gang Zeng at fzeng@uci.edu.

https://doi.org/10.1523/JNEUROSCI.0396-20.2020

Copyright $\odot 2020$ the authors

\section{Introduction}

Subjective tinnitus, or "ringing of the ears," is a phantom sound that can be heard by a person in the absence of any physical sound stimulation (Roberts et al., 2010). Tinnitus affects $\sim 15 \%$ of the population, especially those with hearing loss (HL), older age, noise exposure, and head injury (Baguley et al., 2013; McCormack et al., 2016). Different from auditory hallucinations, which are often associated with meaningful linguistic and musical content, tinnitus typically contains meaningless steady or fluctuating sounds with the quality being tonal, noisy, or a combination of multiple tones and noises (Meikle and Taylor-Walsh, 1984; Stouffer and Tyler, 1990). Previous studies on perceptual aspects of tinnitus focused on two areas. One area was characterizing the perceptual quality of tinnitus via subjective description 
or matching tinnitus loudness, pitch, and spectrum (Reed, 1960; Goodwin and Johnson, 1980; Penner, 1995; Norena et al., 2002; Patuzzi et al., 2004; Moore, 2012). The other area was using various external sounds, from pure tones and noises to modulated sounds and even music, to attempt to mask tinnitus for treatment purposes (Feldmann, 1971; Penner, 1987; Okamoto et al., 2010; Reavis et al., 2012). Surprisingly, much less has been done to answer the reverse question: does tinnitus affect the perception of external sounds? While many individuals with tinnitus complain about hearing difficulty, especially poor speech perception in noise, this hearing difficulty was mostly based on self-report from subjects who had not only tinnitus but also other comorbid factors such as hearing loss and older age (Tyler and Baker, 1983; Andersson et al., 2000; Soalheiro et al., 2012; Vielsmeier et al., 2016; Ivansic et al., 2017). The effect of tinnitus on auditory perception remains understudied, contributing to a lack of effective clinical management of tinnitus.

This knowledge gap has hampered the understanding of the mechanisms underlying tinnitus. Recent animal studies have suggested several neural correlates of tinnitus, ranging from central hyperactivity and maladaptive plasticity to abnormal homeostasis and network connectivity (Muhlnickel et al., 1998; Kaltenbach, 2006; Yang et al., 2011; Chen et al., 2015; Shore and $\mathrm{Wu}, 2019)$. But how do we know whether animals have tinnitus? A "tinnitus filling-in-the-gap" protocol has been widely used to test for the presence of tinnitus by assuming that an animal would have difficulty in detecting a silent temporal gap in a background sound that was qualitatively similar to the tinnitus in animals (Turner et al., 2006). However, human studies have found little evidence for the tinnitus filling-in-the-gap hypothesis, casting doubt on whether previous animal studies actually studied tinnitus or other hearing disorders such as hyperacusis (Campolo et al., 2013; Fournier and Hébert, 2013; Boyen et al., 2015; Möhrle et al., 2019).

To bridge this knowledge gap in tinnitus research, the present study first provided a strong test of the tinnitus filling-in-the-gap hypothesis using a gap stimulus whose frequency and level were matched to the tinnitus pitch and loudness for human subjects. We then compared performance in a range of other psychoacoustical and speech perception tasks between a heterogeneous group of tinnitus subjects and a homogeneous control group of young, normal-hearing, non-tinnitus subjects. We minimized the hearing loss factor by presenting stimuli at a frequency where hearing threshold was normal or using either an equal sensation level (SL) or comfortable level for frequencies where the threshold was elevated. We controlled for the age factor by comparing performance between the young and old tinnitus subjects and comparing performance between the young tinnitus subjects and the young control subjects. Because of the widely held assumption that tinnitus interferes with auditory and speech perception, we hypothesized that tinnitus subjects would perform more poorly than the control group.

\section{Materials and Methods}

Subjects. The University of California Irvine Institutional Research Board approved the experimental protocol. All subjects gave written informed consent to participate in the study. A homogeneous group of 27 young adults (mean \pm SD; age, $22 \pm 2$ years) served as control subjects. These subjects consisted of 11 females and 16 males who were free of tinnitus and had normal hearing thresholds $(\leq 20 \mathrm{~dB} H \mathrm{HL})$ at audiometric frequencies from 125 to $8000 \mathrm{~Hz}$ (Fig. $1 a$, solid black squares). A heterogeneous group of 45 adults (mean age, $44 \pm 15$ years; 18 females and 27 males) who had chronic tinnitus ( $>6$ months) served as experimental subjects. These consisted of 24 old subjects (i.e., $>42$ years old;
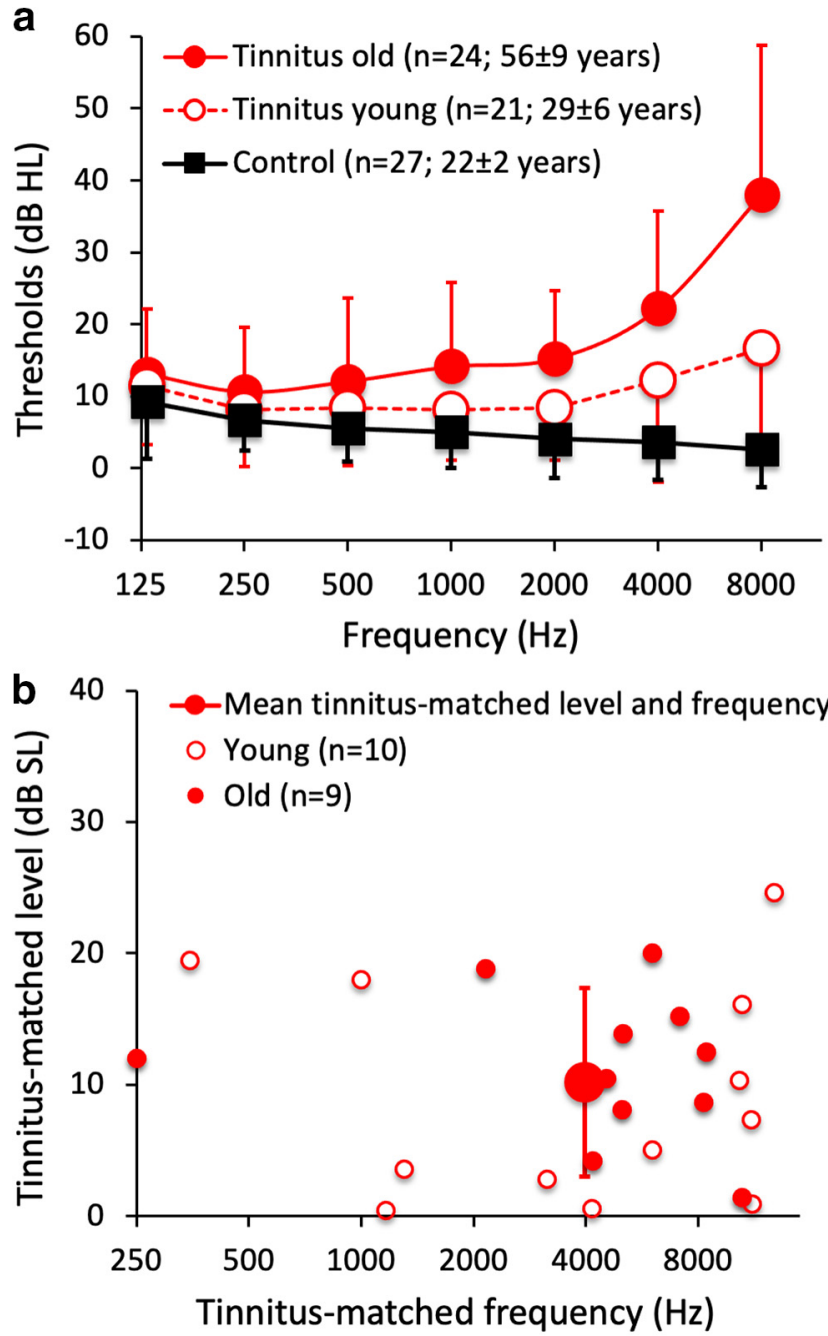

Figure 1. a, Pure-tone audiograms showing hearing thresholds as a function of test-tone frequency for 27 young, normal-hearing control subjects (solid black squares), 21 young tinnitus subjects (open red circles), and 24 old tinnitus subjects (solid red circles). Error bars show \pm 1 SD of the mean. $\boldsymbol{b}$, Tinnitus matching levels ( $y$-axis) and frequencies ( $x$-axis) for 19 tinnitus subjects who participated in gap detection, frequency, and intensity discrimination experiments. The mean tinnitus matching level and frequency are represented by the large solid circle with error bars ( \pm 1 SD). The 19 subjects included 9 old subjects (small solid red circles) and 10 young subjects (small open red circles). There was no significant difference in tinnitus level between the old and young subjects (11.4 \pm 5.4 vs $9.1 \pm 8.4 \mathrm{~dB} \mathrm{SL}$; twotailed, two-sample $t$ test, $p=0.46$ ).

Fig. $1 a$, solid red circles) and 21 young subjects (i.e., $<39$ years old; Fig. $1 a$, open red circles). On average, the old tinnitus subjects had hearing loss $(>20 \mathrm{~dB} \mathrm{HL})$ at 4000 and $8000 \mathrm{~Hz}$, while the young tinnitus subjects had normal hearing at all frequencies. Seven of the 21 young subjects had mild hearing loss (25-40 dB HL) at one or more frequencies, and one had moderate hearing loss (45-50 dB HL) at two frequencies, while the remaining 13 had normal hearing $(\leq 20 \mathrm{~dB} H \mathrm{HL})$ at all frequencies. The individual tinnitus demographic information can be found in Extended Data Fig. 1-1.

All tinnitus subjects, except for two, completed an online questionnaire consisting of the Tinnitus Functional Index (Meikle et al., 2012) and the Tinnitus Handicap Inventory (Newman et al., 1996). They had a mean tinnitus index score of $38 \pm 22$ of 100 . There was no significant difference in tinnitus severity between the old and young tinnitus subjects ( $34 \pm 17$ vs $42 \pm 27$; two-tailed, two-sample $t$ test, $p=0.28$ ). To qualify for the gap detection and frequency and intensity discrimination experiments, 19 of the 45 tinnitus subjects characterized their tinnitus loudness and pitch using a custom adjustment program with a graphical interface. The subjects moved a marker along a horizontal axis to vary 
the frequency of a $500 \mathrm{~ms}$ sinusoid (including $50 \mathrm{~ms}$ cosine-squared ramps) from 250 to $20,000 \mathrm{~Hz}$ on a logarithmic scale and moved a separate marker along a vertical axis to vary the stimulus level from 0 to $100 \mathrm{~dB}$ SPL in $1 \mathrm{~dB}$ steps. The stimulus repeated once every second. The subjects adjusted the stimulus to match as closely as possible the loudness and pitch of their predominant tinnitus component. The stimulus was presented to the ipsilateral ear for unilateral tinnitus or the ear with the louder tinnitus for bilateral tinnitus. Once a match was selected, they rated its similarity to their actual tinnitus using a 0 -to-10 visual analog scale. Finally, to allow for possible octave confusion (Moore and Vinay, 2010), subjects matched the loudness of three tones (the original match, one octave below, and one octave above) to their tinnitus, then selected the one that was most similar in pitch to their tinnitus. If the selection differed from their original match, a new similarity rating was recorded, and this stimulus was taken as their tinnitus match. The subjects rated the matched stimulus to be highly similar to their tinnitus (mean similarity $=8$ of 10). On average, the matched stimulus had a low level of $10 \mathrm{~dB}$ SL but a relatively high frequency (arithmetic mean $=6675 \mathrm{~Hz}$; geometric mean $=3964 \mathrm{~Hz}$; Fig. $1 b$, large solid circle).

Experimental design. Because of time constraints, only a subset of the 45 tinnitus subjects participated in each experiment, ranging from 10 in the overshoot experiment to 31 in the speech-in-noise perception experiment. Information regarding the individual subjects' participation can be found in Extended Data Fig. 1-1.

All experiments, except for speech in noise perception, used the following psychophysical procedure (Zeng et al., 2005b). Briefly, an daptive three-alternative, forced-choice, two-down, and one-up procedure was used to estimate the stimulus value giving $70.7 \%$ correct performance. Each trial consisted of three intervals separated by $400 \mathrm{~ms}$ and marked visually by buttons on a computer interface. The subject had to choose which of the three intervals contained the signal (i.e., the target stimulus that was different from that of standard stimuli in the other two intervals). Pilot experiments established the initial signal strength, making the task easy for the subject at the beginning, and also the step size for adjusting the signal strength throughout the task, making the experiment efficient. Visual feedback of "correct" or "incorrect" after each trial further facilitated learning of the task. Before formal data collection, all subjects received one to three training blocks from equipment adjustment to practice runs to become familiar with the test environment and procedure.

The gap detection experiment used sinusoids, with frequencies of 500,2000 , and $8000 \mathrm{~Hz}$, and additional frequencies matched to each subject's tinnitus pitch. The total duration of the sinusoid was $400 \mathrm{~ms}$, including $40 \mathrm{~ms}$ cosine-squared on and off ramps. The signal contained a temporal gap with $2 \mathrm{~ms}$ cosine-squared offset and onset ramps in the temporal center of the sinusoid; the gap duration was defined by the 6 $\mathrm{dB}$ down points of the gap, and the sinusoidal phase relationship was preserved as if the gap were not present (Shailer and Moore, 1987). The stimulus level was either $10 \mathrm{~dB}$ SL for the frequencies of 500, 2000, and $8000 \mathrm{~Hz}$, or varied between 5 and $15 \mathrm{~dB}$ SL (mean value of $10 \mathrm{~dB}$ SL) for the tinnitus-matched frequencies, depending on the SL of each subject's tinnitus match. The $5 \mathrm{~dB}$ SL lower limit was used because a stimulus level $<5 \mathrm{~dB}$ SL resulted in occasional inaudibility of the stimuli (pilot experiments). The $15 \mathrm{~dB}$ SL upper limit was needed to avoid the use of spectral splatter cues from the $2 \mathrm{~ms}$ gap offset and onset ramps in detecting the gap (pilot experiments; see also Shailer and Moore, 1987). The frequency and intensity discrimination experiments used the same sinusoids as for gap detection, except that the signal was a sinusoid with higher frequency or level, respectively. For these experiments, the stimulus level was fixed at 30 or $70 \mathrm{~dB}$ SL.

The masking and overshoot experiment used a $400 \mathrm{~ms}$ broadband $(100-10000 \mathrm{~Hz})$ white noise and a $10 \mathrm{~ms}, 2000 \mathrm{~Hz}$ tone positioned either at the onset or the temporal center of the noise. Both the noise and tone had $4 \mathrm{~ms}$ cosine-squared onset and offset ramps. The noise spectrum level was 0 and $20 \mathrm{~dB}$ SPL/Hz, corresponding to an overall noise level of 40 and $60 \mathrm{~dB}$ SPL. For subjects with normal hearing, the detection threshold of the tone is typically higher when placed at the onset of the noise compared with its temporal center. The difference in threshold between the two conditions is called the overshoot effect (Zwicker,
1965). The magnitude of the overshoot effect may be influenced by both peripheral and central mechanisms that are relevant to tinnitus (e.g., cochlear gain vs attention filter; see Zeng et al., 2005a). To minimize the influence of hearing loss, which can reduce the overshoot effect (Bacon and Takahashi, 1992), 10 tinnitus subjects were selected with normal hearing ( $\leq 20 \mathrm{~dB} \mathrm{HL}$; mean $=10 \pm 7 \mathrm{~dB} \mathrm{HL})$ at $2000 \mathrm{~Hz}$.

The temporal modulation experiment used three sinusoidal carrier frequencies, 250, 2000, and $8000 \mathrm{~Hz}$, either unmodulated (standard stimulus) or amplitude modulated by a sinusoid (signal) at 4, 41, or $80 \mathrm{~Hz}$. The modulation detection threshold was measured in decibels $(=20 \log m)$, where $m$ is the modulation depth. The level of the modulated signal was adjusted to have the same root mean square level as the unmodulated standard (Viemeister, 1979). Both the signal and the standard were $500 \mathrm{~ms}$ in duration, including $40 \mathrm{~ms}$ cosine-square onset and offset ramps, and presented at $60 \mathrm{~dB}$ SPL or the most comfortable loudness level adjusted by the individual subject.

The speech in noise perception experiment followed a previously described protocol (Zeng et al., 2005c). Briefly, the target speech stimuli were sentences, each containing four to five key words, spoken by a male talker. The three backgrounds were a steady noise with a spectrum matched to the male talker's long-term spectral shape, a competing female talker, and a competing male talker (different from the male target talker). An daptive one-down and one-up procedure was used to estimate the speech-to-background ratio, or speech reception threshold (SRT), that produced $50 \%$ correct performance. A correct response required all key words in the sentence to be correctly identified. No feedback was provided.

Statistics. We used within-subjects ANOVA to assess stimulus effects and between-subjects ANOVA to assess effects of age, hearing, and tinnitus as categorical variables. We used two-way ANOVA to assess interaction effects between each of the within- and between-subjects factors. The age category was either young $(<39$ years old) or old $(>42)$. The hearing category was either normal hearing $(\leq 20 \mathrm{~dB}$ HL at all audiometric frequencies between 125 and $8000 \mathrm{~Hz})$ or hearing loss $(\geq 25 \mathrm{~dB} \mathrm{HL}$ at any audiometric frequencies). Because the binary definition of both the age and hearing factors was arbitrary, including the typically used $20 \mathrm{~dB}$ HL "normal" hearing criterion (Léger et al., 2012; Bernstein and Trahiotis, 2016), we also used age in years and average hearing threshold $(125-8000 \mathrm{~Hz})$ as continuous or scale variables to perform linear correlation and regression. Two-tailed $t$ tests were used to assess the significance of differences, with Bonferroni correction for multiple comparisons. For results meeting the criterion for significance $(p<0.05$, or smaller with correction), effect size was calculated as the difference in means between two distributions divided by their joint SD, with $0.2,0.5$, and 0.8 representing small, medium, and large effects (Cohen, 1969).

\section{Results}

\section{Tinnitus does not affect gap detection}

Even if tinnitus "fills in the gap" in a stimulus, and depending on the stimulus used, tinnitus subjects could potentially still use either an amplitude cue (the stimulus level is higher than the tinnitus level; Fig. $2 a$ ) or a frequency cue (the stimulus and tinnitus have different frequencies; Fig. $2 b$ ) to detect a temporal gap. Theoretically, deficits caused by tinnitus "filling in the gap" would be maximized if the gap stimulus were matched to the tinnitus in amplitude and frequency on an individual basis (Fig. 2c). To minimize the hearing loss factor, we measured gap detection at $10 \mathrm{~dB}$ SL for pure tones with frequencies of 500, 2000, and $8000 \mathrm{~Hz}$ for 10 control subjects (Fig. $2 d$, solid black squares) and 11 tinnitus subjects (Fig. $2 d$, open blue triangles). There was no significant difference in gap detection between control and tinnitus subjects $\left(F_{(1,17)}=0.50, p=0.49\right)$. Neither was there any significant difference when subjects were grouped by hearing loss $\left(F_{(1,17)}=0.47, p=0.51\right)$ or age $\left(F_{(1,17)}=0.33, p=0.57\right)$. Because there was no significant within-subjects effect of frequency $\left(F_{(1,17)}=0.41, p=0.53\right)$, we averaged across frequencies to show 
that the tinnitus and control subjects gave similar gap thresholds of 18 and $21 \mathrm{~ms}$, respectively.

To minimize the use of the frequency cue that might contribute to the lack of tinnitus effect for frequencies of 500, 2000, and $8000 \mathrm{~Hz}$, we matched the gap stimulus to the same subject's tinnitus, and measured gap detection on an individual basis (Fig. $2 d$, small open red circles for young subjects and small solid-red circles for old subjects). On average, the tinnitus subjects gave a gap threshold of $16 \mathrm{~ms}$ at the matched tinnitus frequency (Fig. $2 d$, solid red circle with error bars), which was not significantly different from the $21 \mathrm{~ms}$ threshold for the control group (twotailed, two-sample $t$ test, $p=0.23$ ) or the $18 \mathrm{~ms}$ threshold for the tinnitus group tested at the frequencies of 500,2000 , and $8000 \mathrm{~Hz}$ (two-tailed, paired $t$ test, $p=0.42$ ).

\section{Hearing loss but not tinnitus is associated with frequency discrimination}

Frequency discrimination, expressed as the Weber fraction $(\Delta \mathrm{F} / \mathrm{F})$, was measured for stimulus frequencies of 500,2000 , and $8000 \mathrm{~Hz}$ and for the individually matched tinnitus frequency at $30 \mathrm{~dB}$ SL (Fig. $3 a$ ) and $70 \mathrm{~dB}$ SL (Fig. $3 b$ ) using 10 control and 17 tinnitus subjects. There was no significant difference in frequency discrimination between control and tinnitus subjects at 500, 2000, or $8000 \mathrm{~Hz}\left(F_{(1,22)}=1.89, p\right.$ $=0.18)$. Unlike previous studies showing significant effects of both age and hearing loss (Moore and Peters, 1992), the present study found a significant effect of hearing loss (effect size $=0.20, F_{(1,22)}=5.61$, $p=0.03$ ) but no significant effect of age, probably due to the small sample size $\left(F_{(1,22)}=3.16, p=0.09\right)$. There was a significant interaction between hearing loss and frequency (effect size $=0.22, F_{(2,44)}=6.33, p$ $=0.004)$, which showed that hearing loss impaired frequency discrimination for the $70 \mathrm{~dB} \mathrm{SL}, 8000 \mathrm{~Hz}$ stimulus only $(\Delta \mathrm{F} / \mathrm{F}=0.052$ vs 0.023 ; effect size $=0.22, p=0.02$; Fig. $3 b$, “*”). To test whether hearing loss might confound the present lack of tinnitus effect, results were compared for the five tinnitus subjects with normal hearing and the control subjects. There was no significant difference in frequency discrimination for the 70 $\mathrm{dB}$ SL, $8000 \mathrm{~Hz}$ stimulus among the five tinnitus subjects with normal hearing and the control subjects $(\Delta \mathrm{F} / \mathrm{F}=0.017$ vs 0.029 ; two-tailed, two-sample $t$ test $=0.92, p=0.38$ ). There was no significant difference between the tinnitus data at matched frequencies and the control data at $8000 \mathrm{~Hz}$ for either the $30 \mathrm{~dB}$ SL condition $(\Delta \mathrm{F} / \mathrm{F}=0.023$ vs 0.024 ; two-tailed, two-sample $t$ test, $p$ $=0.98)$ or for the $70 \mathrm{~dB}$ SL condition $(\Delta \mathrm{F} / \mathrm{F}=0.022$ vs 0.027 ; two-tailed, two-sample $t$ test, $p=0.59$ ).

\section{Level-dependent effects of tinnitus on intensity discrimination}

Intensity discrimination was measured at $30 \mathrm{~dB}$ SL (Fig. $4 a$ ) and $70 \mathrm{~dB}$ SL (Fig. 4b) using the 10 control and 17 tinnitus subjects. For intensity discrimination at 500,2000, and $8000 \mathrm{~Hz}$, no significant effects were observed for any of the following three factors: age $\left(F_{(1,22)}=0.01, p=0.91\right)$, hearing loss $\left(F_{(1,22)}=2.51, p=0.13\right)$, and tinnitus $\left(F_{(1,22)}=0.42, p=0.53\right)$. Consistent with previous results (Carlyon and Moore, 1984), there was a significant within-subjects effect of both stimulus frequency (effect size = $\left.0.42 ; F_{(1,22)}=16.18, p=0.001\right)$ and stimulus level (effect size $=$ b

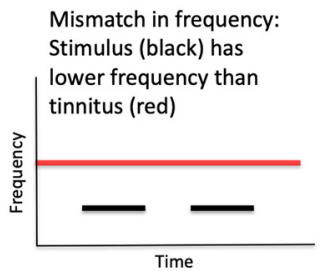

C
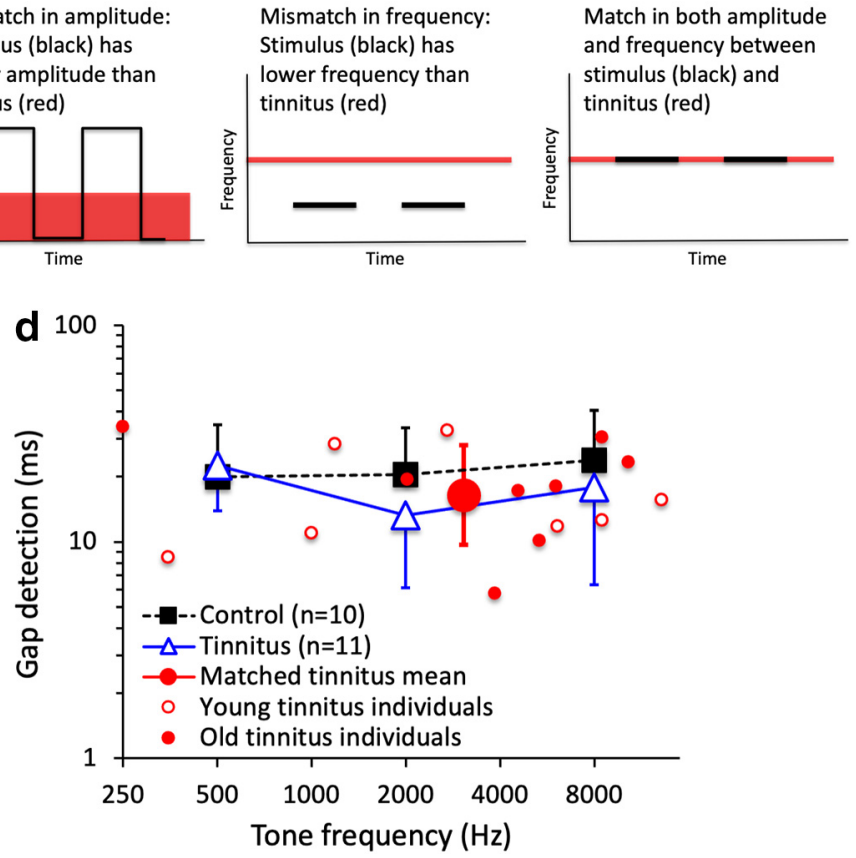

timulus (black) has

higher amplitude than

tinnitus (red)

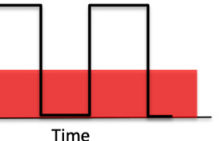

\section{$-$}

Figure 2. Gap detection experimental design and data. $\boldsymbol{a}$, Use of an amplitude cue for gap detection by (small solid red circles). There was no significant difference in gap at tinnitus-matched frequencies between the young and old tinnitus subjects (17 vs $15 \mathrm{~ms}$; twoiled, two-sample $t$ test, $p=0.60$ ). Four subjects matched their tinnitus pitches to two different frequencies, tal of 15 data points. Error bars show \pm 1 SD of the mean.

$\left.0.79 ; F_{(1,22)}=82.70, p<0.001\right)$. On average, the $1.7 \mathrm{~dB}$ threshold at $500 \mathrm{~Hz}$ was better than the $2.7 \mathrm{~dB}$ threshold at $8000 \mathrm{~Hz}$ (effect size $=-0.84 ; p=0.002$ with Bonferroni correction); the $2.9 \mathrm{~dB}$ threshold at $30 \mathrm{~dB}$ SL was poorer than the $1.5 \mathrm{~dB}$ threshold at $70 \mathrm{~dB}$ SL (effect size $=0.79 ; p<0.001$ with Bonferroni correction).

A level-dependent pattern emerged for intensity discrimination at the tinnitus-matched frequencies. At $70 \mathrm{~dB}$ SL, the $1.3 \mathrm{~dB}$ threshold at the tinnitus-matched frequency was not significantly different from the $1.9 \mathrm{~dB}$ threshold for the control subjects at $8000 \mathrm{~Hz}$ (two-tailed, two-sample $t$ test, $p=0.22$ ). However, at $30 \mathrm{~dB}$ SL, tinnitus subjects gave a $2.5 \mathrm{~dB}$ intensity discrimination threshold at the tinnitus-matched frequency, which was significantly better than the $4.1 \mathrm{~dB}$ control value at $8000 \mathrm{~Hz}$ (effect size $=-0.84$; two-tailed, two-sample $t$ test, $p=0.04$ ). This improvement might be an effect of loudness recruitment due to hearing loss in some of the present tinnitus subjects, which can give better than normal intensity discrimination when the comparison is made at an equal SL (Moore, 1996). Additional analysis was performed to test the loudness recruitment hypothesis. First, at the same $30 \mathrm{~dB} \mathrm{SL}$, the sound pressure level was not significantly higher for the present tinnitus subjects than for the control subjects $(51 \pm 11$ vs $44 \pm 11 \mathrm{~dB}$ SPL; two-tailed, two-sample $t$ test, $p=0.11$ ). Second, had loudness recruitment played a significant role in the present result, better intensity discrimination would be correlated with higher sound pressure levels for a fixed SL. No such correlation was found $(r=0.17, p=0.56)$, suggesting that 

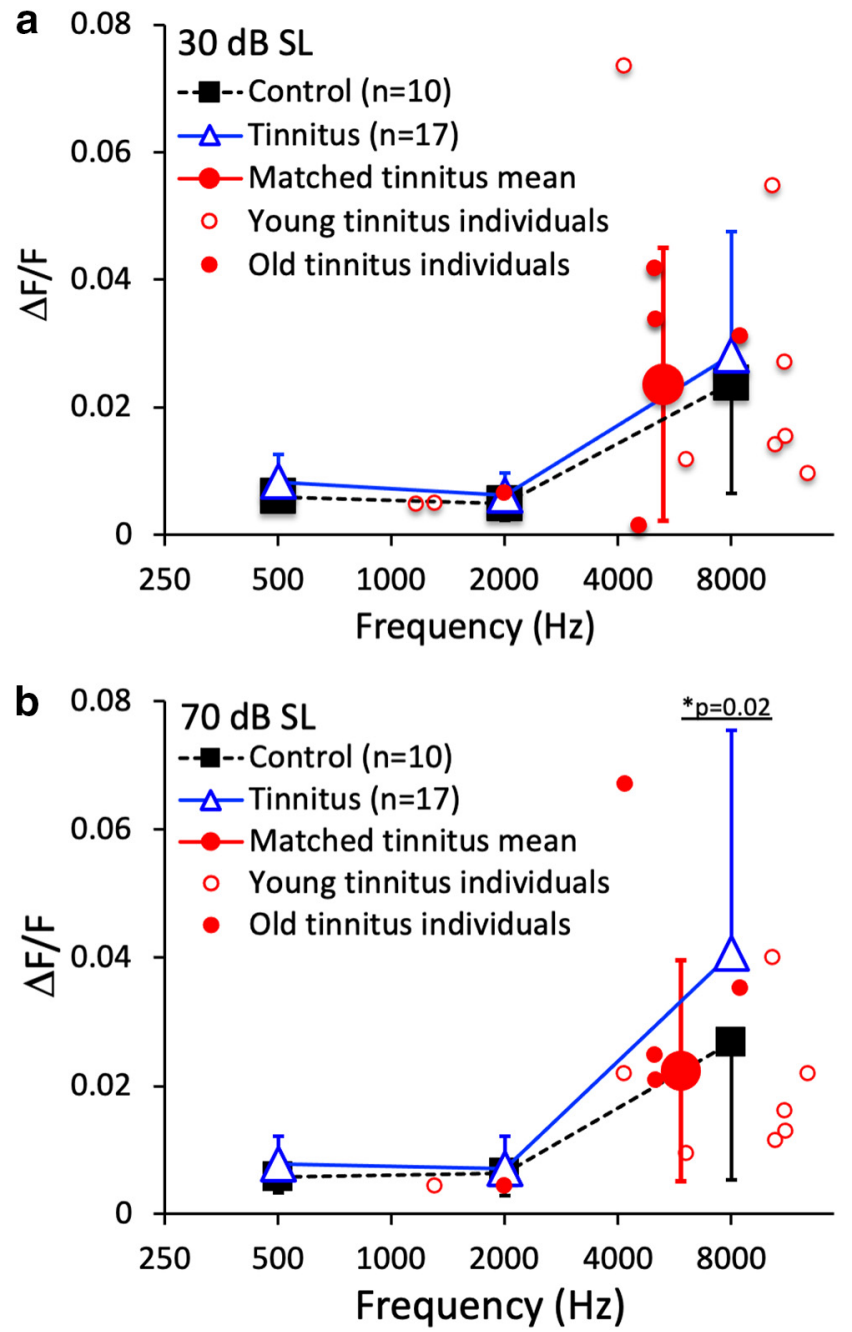

Figure 3. Frequency discrimination. $\boldsymbol{a}$, The Weber's fraction as a function of frequency at $30 \mathrm{~dB}$ SL for 10 control subjects (solid black squares) and 17 tinnitus subjects (open blue triangles). Error bars show \pm 1 SD of the mean. The average threshold for tinnitus-matched stimuli (the large solid red circle with error bars) was the arithmetic mean for 14 tinnitus subjects, including 9 young (small open red circles) and 5 old (small solid red circles). $\boldsymbol{b}$, The same as $\boldsymbol{a}$, except at $70 \mathrm{~dB}$ SL. The asterisk and the line below represent a significant difference between the groups. There was no significant difference in frequency discrimination between the young and old tinnitus subjects at the matched frequencies ( 0.021 vs 0.027 ; two-tailed, two-sample $t$ test, $p=0.45$ ).

the $1.6 \mathrm{~dB}$ improvement in intensity discrimination at $30 \mathrm{~dB} \mathrm{SL}$ was more related to tinnitus than to loudness recruitment.

\section{Level-dependent effects of tinnitus on masking and} overshoot

We measured detection of a short tone in broadband noise, with the tone being presented at the onset of a noise masker (Fig. 5a) or at the temporal center of the masker (Fig. $5 b$ ), for noise spectrum levels of 0 and $20 \mathrm{~dB} \mathrm{SPL} / \mathrm{Hz}$. There was no significant effect of age $\left(F_{(1,21)}=2.47, p=0.13\right)$, hearing loss $\left(F_{(1,21)}=0.39, p\right.$ $=0.54)$, or tinnitus $\left(F_{(1,21)}=0.69, p=0.42\right)$. For the temporal center condition, the slope of the masking growth function was 1.0 for both the control (Fig. $5 c$, solid squares) and tinnitus (Fig. $5 d$, solid triangles) subjects. For the onset condition, the slope of the masking function was 1.3 for both the control and tinnitus subjects, which was significantly steeper than for the center condition (effect size $=1.78, F_{(1,21)}=38.38, p<0.001$ ). The control


Figure 4. Intensity discrimination. $\boldsymbol{a}$, Intensity discrimination threshold as a function of frequency at $30 \mathrm{~dB}$ SL for 10 control subjects (solid black squares) and 16 tinnitus subjects (open blue triangles). Error bars show \pm 1 SD of the mean. The average threshold for tinnitus-matched stimuli (the solid red circle with error bars) was the arithmetic mean from 14 tinnitus subjects, including 9 young (small open red circles) and 5 old (small solid red circles). The asterisk and the line below represent a significant difference between the groups. $\boldsymbol{b}$, The same as $\boldsymbol{a}$ except at $70 \mathrm{~dB}$ SL. There was no significant difference in intensity discrimination at tinnitus-matched frequencies between the young and old tinnitus subjects at either $30 \mathrm{~dB}$ $\mathrm{SL}(p=0.10)$ or $70 \mathrm{~dB} S \mathrm{~L}$ (two-tailed, two-sample $t$ test, $p=0.61$ ).

subjects produced no significant overshoot at the $0 \mathrm{~dB}$ noise level ( $1 \mathrm{~dB}$; two-tailed, paired $t$ test, $p=0.28$ ) but significant overshoot at the $20 \mathrm{~dB}$ noise level $(7 \mathrm{~dB}$; effect size $=2.51 ; p<0.001)$. Had hearing sensitivity played a role, reduced overshoot would be expected for the tinnitus subjects. On the contrary, they produced significant overshoot at both noise levels $(2 \mathrm{~dB}$ at $0 \mathrm{~dB}$ : effect size $=0.81, p=0.015 ; 8 \mathrm{~dB}$ at $20 \mathrm{~dB}$ : effect size $=2.16$, $p<0.001$; Fig. 5e). Moreover, no significant correlation was observed between the hearing threshold at $2000 \mathrm{~Hz}(\leq 20 \mathrm{~dB} \mathrm{HL})$ and the overshoot value $(r=0.28, p=0.44)$, suggesting that the enhanced overshoot effect at the $0 \mathrm{~dB}$ noise level was related to tinnitus.

No effect of tinnitus on temporal modulation detection We measured temporal modulation detection as a function of carrier frequency $(250,2000$, and $8000 \mathrm{~Hz})$ for modulation frequencies of $4 \mathrm{~Hz}$ (Fig. 6a), $41 \mathrm{~Hz}$ (Fig. 6b), and $80 \mathrm{~Hz}$ (Fig. 6c). There was no significant effect of age $\left(F_{(1,34)}=1.01, p=0.32\right)$, hearing loss $\left(F_{(1,34)}=0.71, p=0.41\right)$, or tinnitus $\left(F_{(1,34)}=0.25, p\right.$ 
$=0.62)$. There were significant within-subject effects for the modulator (effect size $=0.75$, $\left.F_{(2,68)}=103.05, p<0.001\right)$ and the carrier (effect size $=0.15, F_{(2,68)}=5.71, p=0.005$ ), but no significant interactions with any subject variables $(p>0.45)$.

Interactive effects of tinnitus, age, and hearing loss on speech perception in noise We estimated the SRT for the following three backgrounds: a steady noise, a male talker, and a female talker (Fig. 7). There was no significant effect of age $\left(F_{(1,45)}=3.47, p=0.07\right)$, hearing loss $\left(F_{(1,45)}=0.55, p=0.46\right)$, or tinnitus $\left(F_{(1,45)}=0.10, p=0.75\right)$. There was a significant effect of background type (effect size $=0.83$, $\left.F_{(2,90)}=235.55, p<0.001\right):$ the steady noise produced the highest SRT $(-0.1 \mathrm{~dB})$, followed by the male talker $(-3.8 \mathrm{~dB})$ and the female talker $(-14.0 \mathrm{~dB})$. There was a significant interaction between age and background, with only the female talker producing a significant effect of age (effect size $=0.57, F_{(2,90)}=3.4, p=0.04$ ). We further analyzed the effect of age based on tinnitus by comparing the young and old tinnitus subjects with the young control subjects. The young tinnitus subjects outperformed the old tinnitus subjects by $4.5 \mathrm{~dB}$ (effect size $=$ 1.08, two-tailed, two-sample $t$ test, $p=0.01$ ) and, surprisingly, the young control subjects by $3.0 \mathrm{~dB}$ (effect size $=0.86$, two-tailed, two-sample $t$ test, $p=0.03$ ).

In addition to treating age, hearing, and tinnitus as categorical variables, we calculated the correlation between the SRTs from the 31 tinnitus subjects and their age, average audiometric threshold, and tinnitus severity index (Extended Data Fig. 1-1). After correcting for multiple comparisons, the female-talker SRT was the only measure that significantly correlated with age $(r=0.43, p=0.015)$ and the average audiometric threshold $(r=0.51, p=$ 0.003). Multiple regression analysis further showed that age accounted for $19 \%$ of the variance in the female-talker SRT data, while the average thresholds accounted for an additional $12 \%$.

\section{Attention-normalization model}

We propose an attention-normalization model to account for the perceptual relationship between stimulus (s) and tinnitus (t; Fig. $8 a$ ). The physical stimulus, as an external sound, travels through a traditional bottom-up pathway to form a percept (Ps) in the bottom-left box. However, the tinnitus, as an internal sound, travels through an independent top-down pathway to form a percept $(P t)$ in the top-left box (Jastreboff, 1990; Sedley et al., 2016). Because these two pathways do not overlap, the tinnitus and stimulus percepts only influence each other through an attention normalization mechanism (Reynolds and Heeger, 2009), in which the total percept $(P)$ is determined by the sum of attention-weighted tinnitus percept

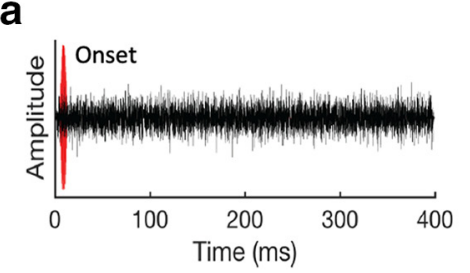

b
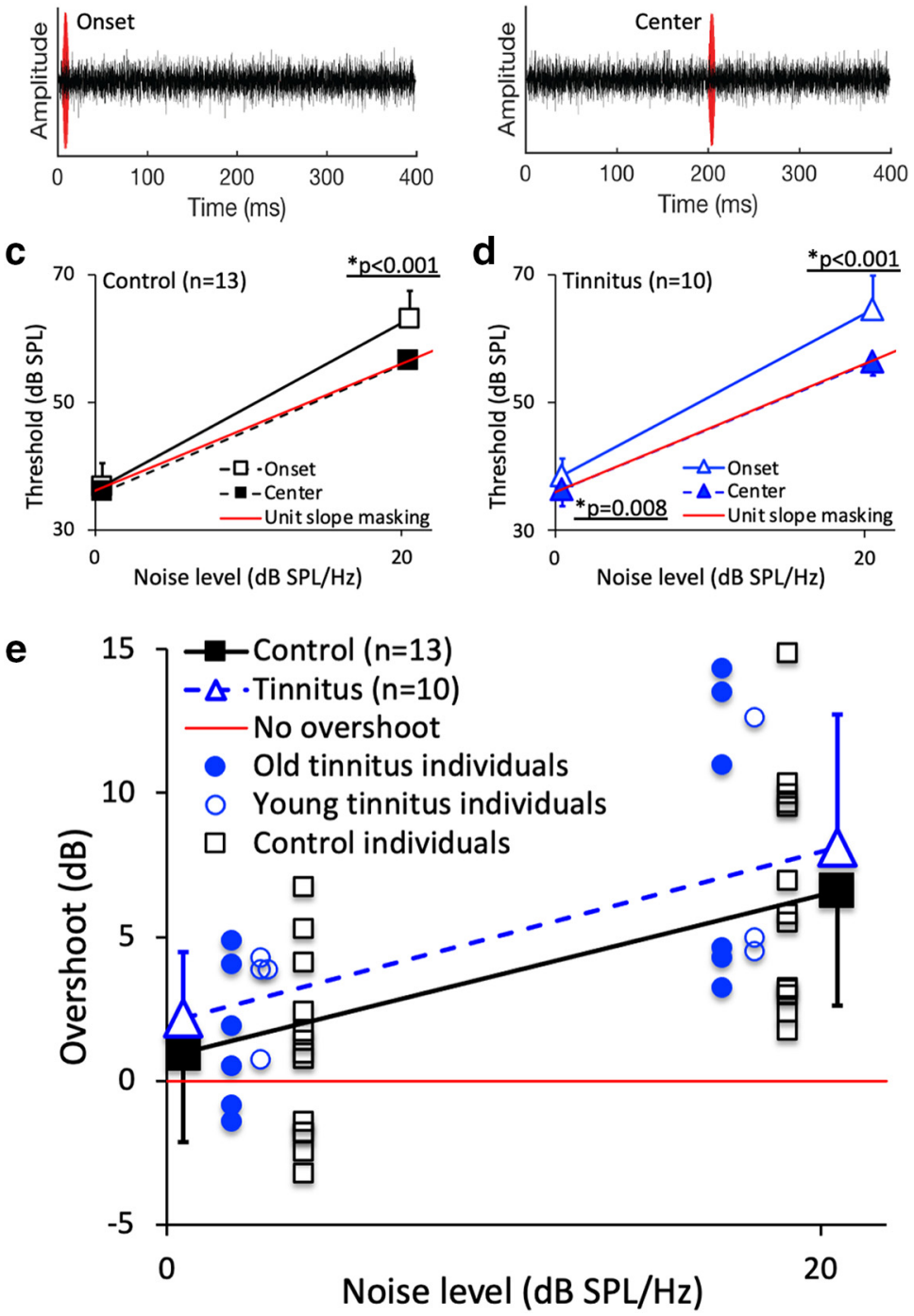

Figure 5. Temporal masking and overshoot. $\boldsymbol{a}$, Onset masking condition: detection of a $10 \mathrm{~ms}, 2000 \mathrm{~Hz}$ tone (red waveform) positioned at the onset of $400 \mathrm{~ms}$ broadband $(100-10000 \mathrm{~Hz})$ white noise (black waveform). $\boldsymbol{b}$, Centermasking condition: detection of the same signal positioned at the temporal center of the $400 \mathrm{~ms}$ noise. c, Masking growth functions for 13 control subjects. Detection threshold as a function of the noise level for the onset (open squares) and center (solid squares). The solid red line represents a slope of 1 . The asterisk and the line below represent a significant difference between the groups at the $20 \mathrm{~dB}$ noise level. $\boldsymbol{d}$, Masking growth functions for 10 tinnitus subjects. The symbols have the same meanings as those in c, except for the blue colors and triangles. The asterisk and the line below represent a significant difference between the groups at the 0 and $20 \mathrm{~dB}$ noise levels. $\boldsymbol{e}, 0$ vershoot functions for the average tinnitus subjects (open blue triangles) and control subjects (solid black squares). Individual overshoot data include six old tinnitus subjects (solid blue circles), five young tinnitus subjects (open blue circles), and 13 control subjects (open black squares). The solid red line represents no overshoot, namely no difference in tone detection threshold between the onset and center conditions. Error bars show \pm 1 SD of the mean. There was no significant difference in overshoot between the old and young tinnitus subjects (solid vs open circles in $\boldsymbol{e} ; p=0.29$ for 0 $\mathrm{dB}$ noise and $p=0.75$ for $20 \mathrm{~dB}$ noise).

and stimulus percept $\left(a_{t} P_{t}+a_{s} P_{s}\right)$ over the total level of attention $\left(a_{t}+a_{s}\right)$, as follows:

$$
P=\frac{a_{t} P_{t}+a_{s} P_{s}}{a_{t}+a_{s}} .
$$

The tinnitus, stimulus, and total percepts $\left(P_{t}, P_{s}, P\right)$ are multidimensional, including loudness, pitch, time and other components, but we focus on loudness here. To illustrate the interactive role of attention in tinnitus and stimulus perception, we fix the 

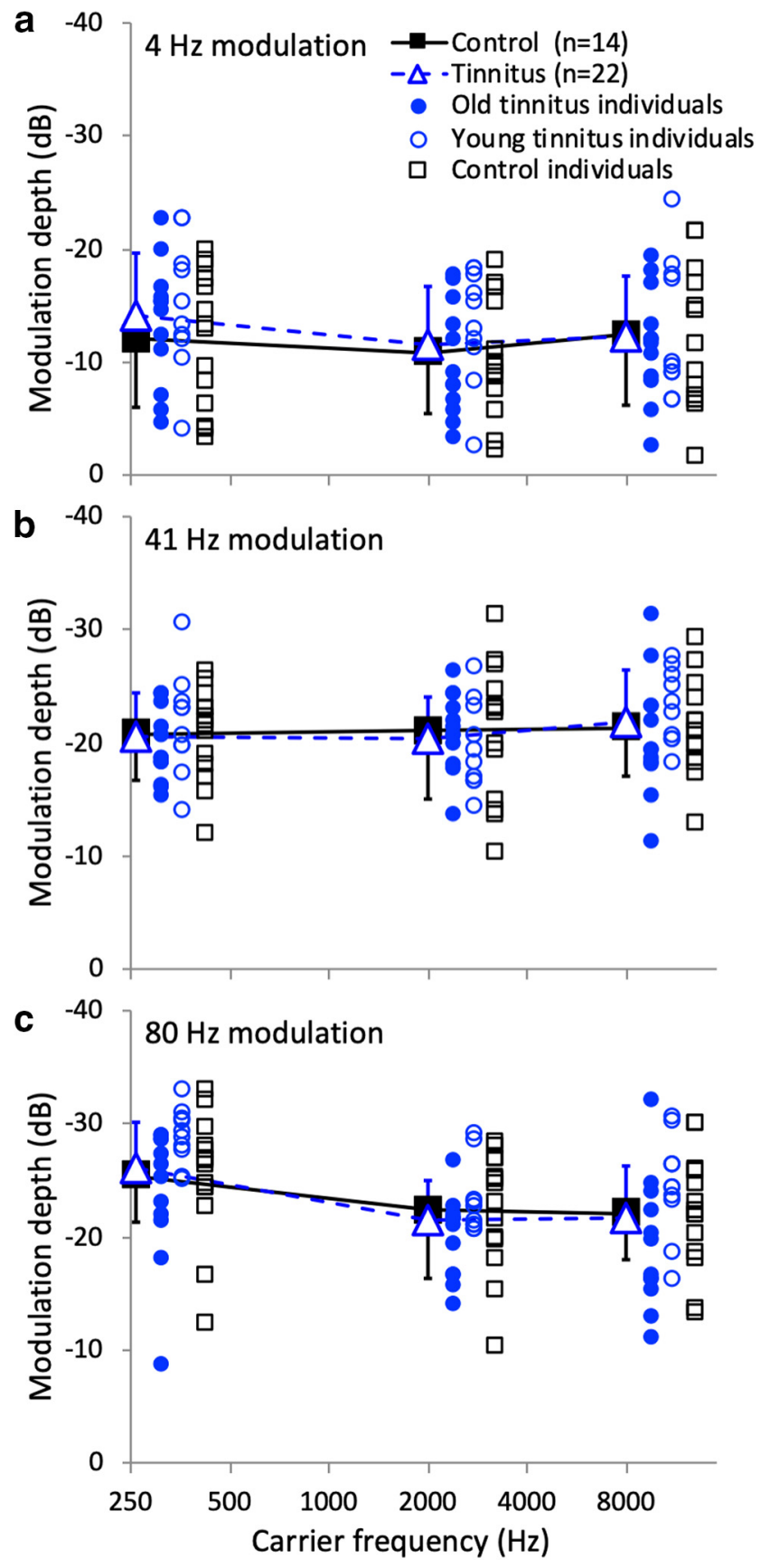

Figure 6. Temporal modulation detection. $\boldsymbol{a}$, Detection threshold of $4 \mathrm{~Hz}$ sinusoidal amplitude modulation as a function of carrier frequency $(250,2000$, and $8000 \mathrm{~Hz})$. The open blue triangles show the average threshold for 22 tinnitus subjects, and the solid black squares show the average threshold for 14 control subjects. The solid blue circles represent individual data for the 12 old tinnitus subjects, open blue circles for the 10 young tinnitus subjects, and black open squares for the 14 control subjects. Error bars show \pm 1 SD of the mean. $\boldsymbol{b}$, The same as $\boldsymbol{a}$, except for detecting $41 \mathrm{~Hz}$ modulation. $\boldsymbol{c}$, The same as $\boldsymbol{a}$ except for detecting 80 $\mathrm{Hz}$ modulation.

baseline tinnitus loudness and attention level $\left(P_{t}=50\right.$ and $a_{t}=$ $0.5)$. In this case, the tinnitus loudness is $\frac{a_{t} P_{t}}{a_{t}+a_{s}}=\frac{0.5 * 50}{0.5+a_{s}}$, which has a value of 50 when no attention is paid to the stimulus (i.e., $a_{s}=$ 0 ; Fig. $8 b, y$-axis intercept for the red dashed line). We liken this scenario to performing a tinnitus loudness-rating task, where the external sound is absent. However, when an external sound is present (e.g., performing a tinnitus loudness-matching task), the tinnitus loudness decreases with increased attention to the

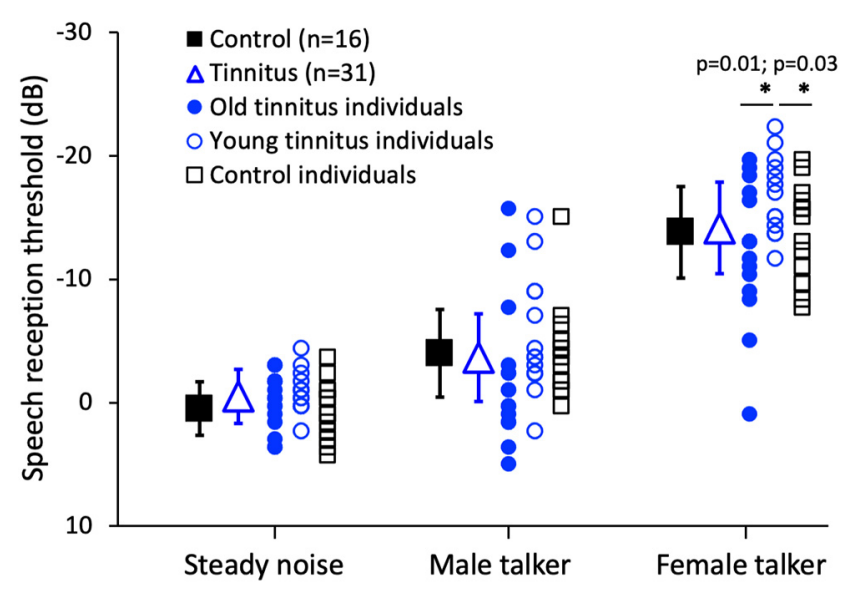

Figure 7. SRTs for three backgrounds. The solid black squares represent the average SRTs for 16 control subjects, and the open blue triangles represent the average SRTs for 31 tinnitus subjects. Individual data are shown by blue solid circles for 18 old tinnitus subjects, blue open circles for 13 young tinnitus subjects, and black open squares for 16 control subjects. Error bars show $\pm 1 S D$ of the mean. The asterisk and the line below represent significant differences between the groups for the female talk background.

stimulus (Fig. 8b, red dashed line). We then calculate how the stimulus loudness $\left(\frac{a_{s} P_{s}}{a_{t}+a_{s}}\right)$ varies with attention $\left(a_{s}\right)$ for four stimulus baseline levels (i.e., $P_{s}=100,50,25$, and 10; Fig. 8b, four black lines from top to bottom). The intersections between the red dashed line and the black lines (Fig. $8 b$, blue circles) indicate that the same 50-loud tinnitus can be matched in loudness to four different levels of an external stimulus, dependent on the relative levels of attention to the tinnitus and the stimulus. The model predicts a strong role of attention, making it possible to reconcile the puzzling discrepancy between loud tinnitus rating (e.g., $P_{t}=$ 50 for $a_{s}=0$ ) and tinnitus matching to a low-level sound (e.g., $P_{s}$ $=10$ for $a_{s}=2$ ). This factor of five change in loudness due to attention is not impossible, as a factor of four effect of attention on loudness was previously observed (Schlauch, 1992).

The model can predict the effects of tinnitus on loudness growth for an external stimulus as a function of its intensity. At present, we do not know how attention varies with loudness, but it is reasonable to assume that a louder percept is associated with more attention. In the interest of simplicity, we assume attention is a linear function of loudness, namely, $a_{t}=\alpha P_{t}$ and $a_{s}=\alpha P_{s}=$ $\alpha I^{0.3}$ (Stevens's power law), where $\alpha$ is a constant and $I$ is stimulus intensity. The total loudness of tinnitus and stimulus is obtained by rewriting Equation 1 as follows:

$$
P=\frac{\alpha P_{t}^{2}+\alpha P_{s}^{2}}{\alpha P_{t}+\alpha P_{s}}=\frac{P_{t}^{2}+I^{0.6}}{P_{t}+I^{0.3}} .
$$

At low stimulus levels, $I^{0.3} \ll P_{t}$, so the total loudness $P \approx P_{t}$, which serves as a floor due to tinnitus (Fig. $8 c$, far left part of the blue lines). At high stimulus levels, $I^{0.3} \gg P_{t}$, so the total loudness was $P \approx I^{0.3}$, following normal loudness growth (Fig. $8 c$, far right part of the blue lines). This prediction is consistent with the idea of conceptualizing tinnitus as internal noise, which increases the loudness estimates at low stimulus levels but not the slope of the loudness function (Zeng, 2013).

The present attention-based model can also explain several puzzling tinnitus phenomena. For example, the traditional energy-based model cannot explain why sometimes soft, lowfrequency, and dynamic stimuli can mask loud, high-pitched, and steady tinnitus (Vernon and Meikle, 1981; Zeng et al., 2011; 
Reavis et al., 2012). Our model suggests that the tinnitus is reduced because greater attention is paid to the soft, lowfrequency, and dynamic stimuli than the tinnitus, similar to the tinnitus-matching scenario (Fig. 8b). It would be equally difficult for the traditional model to explain why sometimes tinnitus cannot be masked by any external sounds at all (Penner, 1987). Our model can explain this unmaskability of tinnitus by assuming the separate pathways between tinnitus and stimulus (Fig. 8a) and the subject's inability to ignore tinnitus $\left(a_{t}>\right.$ $0)$. Finally, the traditional model cannot explain how tinnitus occasionally could improve auditory performance (e.g., intensity discrimination; Fig. 4a) and perception of male speech in the presence of a female talker (Fig. $7 a$ ). We note that the tinnitus-improved performance occurred at relatively low stimulus levels $(30 \mathrm{~dB}$ SL for intensity discrimination and $-14 \mathrm{~dB}$ SRT for the female-talker background). We speculate that tinnitus increases attention to the low-level stimuli (Fig. 8c) so that a "spotlight" strategy can be used to improve auditory performance at these low levels (Luce and Green, 1978; Leek et al., 1991).

\section{Discussion}

The present study compared performance between tinnitus and control subjects in 36 perceptual measures (4 in gap detection, 16 in frequency and intensity discrimination, 4 in masking, 9 in temporal modulation detection, and 3 in speech-innoise perception). Contradictory to the hypothesis, we found that tinnitus does not affect performance in 32 of the 36 measures. We found one instance of worsened performance with tinnitus (Fig. $3 b$; but the worsened frequency discrimination might be due to hearing loss), and three instances of improved or enhanced performance with tinnitus (Fig. $4 a$, intensity discrimination; Fig. $5 d$, overshoot; Fig. 7, speech perception). Because these four significant differences were all relatively small and the majority (32 of 36) of the measures did not show any significant effect, we conclude that tinnitus does not interfere with auditory and speech perception in general. We interpret this lack of the effect of tinnitus on auditory perception as a result of two independent pathways between the tinnitus and external sounds. The separate pathways make it difficult to perfectly match an external sound to tinnitus, and even if they were matched, the tinnitus would not interfere with the sound physically, to "fill in temporal gaps," as described by the traditional energy-based model.

\section{Comparison with previous studies}

There are few previous studies on the perceptual effects of tinnitus. In seven previous gap-detection studies using human

a blue diagonal line.
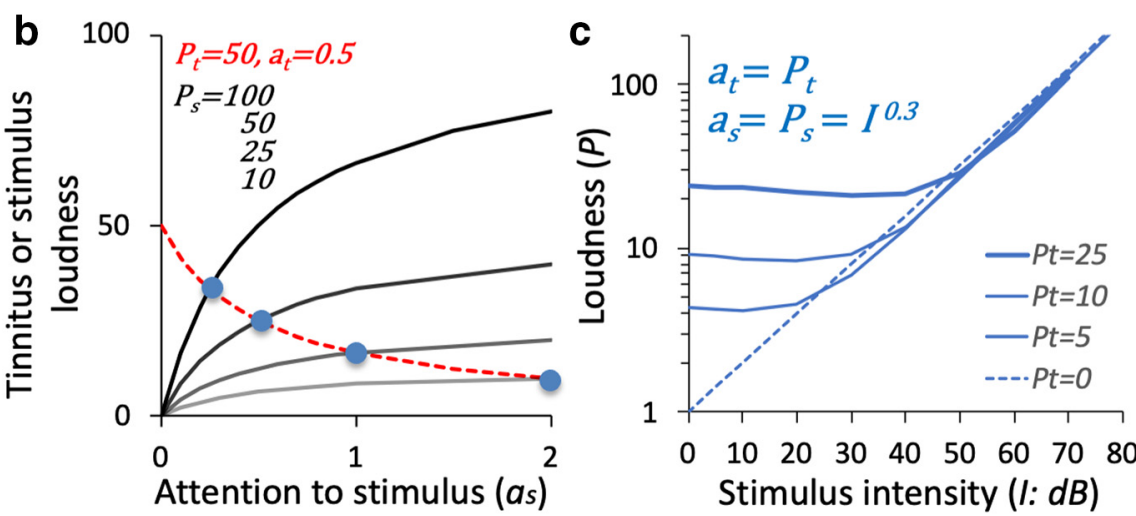

Figure 8. Tinnitus attention-normalization model and predictions. $\boldsymbol{a}$, Tinnitus $(\mathrm{t})$ is of an internal origin and goes through a top-down pathway to produce a tinnitus percept $P_{t}$. A physical stimulus $(s)$ is of an external origin and goes through an indetinnitus; $a_{s}=$ attention to stimulus) to produce a total percept $P$, which is the sum of the attention-weighted individual perstimulus. For a tinnitus baseline loudness at 50 and tinnitus attention level at 0.5 , tinnitus loudness $\left(P_{t}=\right.$ red dashed line) decreases with increased attention to stimulus ( $x$-axis). For four stimulus loudness baseline levels $(100,50,25$, and 10 repreThe intersections between the tinnitus curve and the four stimulus curves (blue circles) indicate equal loudness between tinnitus and stimulus. $c$, Prediction of the effect of tinnitus on loudness growth for an external stimulus. The total loudness $(P)$ 10 , and 5 as three solid blue lines, respectively). The loudness growth function without tinnitus $\left(P_{t}=0\right)$ is shown by the dotted

tinnitus subjects, four observed a small gap-detection deficit (1$4 \mathrm{~ms}$ worse than the normal) for tinnitus subjects (Sanches et al., 2010; Mehdizade Gilani et al., 2013; Jain and Dwarkanath, 2016; Ibraheem and Hassaan, 2017), but the other three did not find any deficit (An et al., 2014; Boyen et al., 2015; Morse and Vander Werff, 2019). By assessing gap detection using gap stimuli matched to the loudness and pitch of the tinnitus (Fig. $2 c$ ), the present study has provided the strongest evidence against the tinnitus filling-in-the-gap hypothesis.

One study reported that frequency discrimination is impaired for subjects with moderate tinnitus but not for those with mild tinnitus (Jain and Sahoo, 2014). In terms of intensity discrimination, one study found a $1 \mathrm{~dB}$ deficit in two of nine test conditions (Epp et al., 2012), while the other found no effect of tinnitus (Jain and Sahoo, 2014). We did not find any masking studies 
using a flat-spectrum broadband noise but found two studies using the "threshold-equalizing-noise" (Moore et al., 2000) to detect dead cochlear regions in tinnitus subjects (Weisz et al., 2006; Buzo and Carvallo, 2014). Both studies found a significant masking effect, but none showed a masked signal threshold that was $\geq 10 \mathrm{~dB}$ than the control, as required for the detection of a dead region (Moore et al., 2000). There was no previous study of the effect of tinnitus on overshoot. One of the two studies on temporal modulation detection found no effect of tinnitus except for improved detection $(\sim 2 \mathrm{~dB})$ of $10 \mathrm{~Hz}$ sinusoidal modulation in the tinnitus ear relative to the non-tinnitus ear for a group of unilateral tinnitus subjects with normal audiograms (Moon et al., 2015). The other study found no effect of tinnitus on the detection of $19 \mathrm{~Hz}$ modulation of a $500 \mathrm{~Hz}$ carrier, but found worse performance $(2 \mathrm{~dB})$ for a $5000 \mathrm{~Hz}$ carrier in tinnitus subjects (Paul et al., 2017). Overall, like the present study, these previous studies found either a small or nonsignificant effect of tinnitus on auditory perception.

Despite widespread self-report of poor speech perception, especially in noise, by tinnitus subjects (Ivansic et al., 2017), previous studies actually found little or no deficits when age and hearing loss were carefully controlled $(0-2 \mathrm{~dB}$ differences in SRTs; Moon et al., 2015; Gilles et al., 2016; Tai and Husain, 2018). Two mechanisms may underlie the previous and present results. On the one hand, tinnitus can be subjectively loud and annoying, but most often its matched level is low at 10-20 dB SL, and its matched frequency high at $>4000 \mathrm{~Hz}$ (Reed, 1960; Pan et al., 2009; Fig. 1b). In contrast, speech sounds have a conversational level at $\geq 50 \mathrm{~dB} \mathrm{SL}$, and most energies at frequencies $<4000 \mathrm{~Hz}$ (Studebaker et al., 1987; Cox et al., 1988). These level and frequency differences between speech and tinnitus would predict the lack of an effect of tinnitus on speech perception. On the other hand, an attention-related mechanism may explain how the young tinnitus subjects performed better than the young control subjects in the male target and female background condition (Fig. 7). Because the male and female talkers represent two separate auditory objects, the tinnitus-enhanced "spotlight" may improve perception of the male talker while ignoring the female background (Luce and Green, 1978; Leek et al., 1991).

\section{Comparison with other hearing disorders}

Cochlear hearing loss, the most common hearing disorder, produces higher thresholds, broader frequency tuning, and poorer speech performance in noise than for normal control subjects (Moore, 1996). The perceptual consequences are different between tinnitus and cochlear loss. First, tinnitus and cochlear loss are correlated, but this correlation is neither necessary nor sufficient, because some tinnitus subjects have normal thresholds while some hearing-impaired subjects have no tinnitus (Axelsson and Ringdahl, 1989; Henry et al., 2005). Second, tinnitus subjects with normal hearing have a similar tip but lowered tails of the tuning curve than non-tinnitus, normal-hearing control subjects (Buzo and Carvallo, 2014). If both tinnitus and non-tinnitus subjects have hearing loss, then the tinnitus subjects have sharper tuning than the non-tinnitus control subjects (Tan et al., 2013). These perceptual differences likely reflect the different pathophysiologies between cochlear hearing loss (damage to hair cells and other cochlear structures) and tinnitus (e.g., selective loss of low-spontaneous rate neurons; Furman et al., 2013).

Tinnitus is similar to, yet different from, auditory neuropathy, a hearing disorder that is characterized by normal cochlear amplification but abnormal neural activity (Starr et al., 1996). People with either tinnitus or auditory neuropathy may present with normal audiometric thresholds, but their suprathreshold processing deficits are different. Auditory neuropathy impairs temporal processing (Zeng et al., 2005b), but tinnitus does not (the present gap and modulation results). Auditory neuropathy is characterized by speech recognition that is poorer than expected from reduced audibility (Zeng and Liu, 2006). In contrast, tinnitus rarely impairs speech perception in quiet (Tai and Husain, 2019), and its effect on speech perception in noise is minimal (the present study).

Tinnitus shares some attributes associated with central auditory processing disorder. For example, both disorders can produce poorer speech in noise perception in the left ear than the right ear (Bellis et al., 2008; Tai and Husain, 2019). Tinnitus is associated with impaired cognitive processing, working memory, and selective attention in cross-modality processing (Andersson et al., 2000; Hallam et al., 2004; Dornhoffer et al., 2006; Rossiter et al., 2006; Stevens et al., 2007; Araneda et al., 2015; Husain et al., 2015; Li et al., 2018). At present, the relationship between tinnitus and central auditory processing disorder remains unclear because most of these studies did not control for the comorbid age and hearing loss factors that may also contribute to the observed cognitive impairment (Dupuis et al., 2015; Mohamad et al., 2016).

\section{Significance}

The present study suggests that tinnitus does not interfere with the perception of external sounds; thus, it is unlikely to be "filling-in-the-temporal-gap." Instead, future tinnitus animal model studies may consider two alternatives. First, the presence of tinnitus in animals increases the level of central noise, which can be measured directly (Möhrle et al., 2019) or indirectly (Jones et al., 2013). Second, the presence of tinnitus in animals increases the level of attention (Roberts et al., 2013), with one recent study showing increased vigilance but impaired attention in rats with tinnitus (Brozoski et al., 2019). The present attention-based model predicts increased attention to tinnitus-like sounds; thus, a biomarker of attention (Jacobson et al., 1996) can be used to detect not only the presence of tinnitus, but also the specific affected frequency region in animal model studies.

If tinnitus does not impair the perception of external sounds, why then do many individuals with tinnitus complain about hearing difficulty? We believe that this hearing difficulty is due to tinnitus comorbid conditions and secondary effects. First, most individuals with tinnitus have some degree of hearing loss, which impairs both audibility and suprathreshold processing to directly contribute to the hearing difficulty (Moore, 1996). Second, some individuals with tinnitus have comorbid hyperacusis (Jastreboff and Jastreboff, 2000), which reduces their dynamic range and forces them to listen to soft sounds under less favorable conditions. Third, tinnitus may increase cognitive load, and induce stress, fatigue, or even fear, resulting in subjective complaints about hearing difficulty (Jagoda et al., 2018; Zhang et al., 2018). Because tinnitus has no cure at present and tinnitus does not affect auditory and speech perception, clinicians may deliver greater benefit and satisfaction to individuals with tinnitus by treating their comorbid conditions and secondary effects than by attempting to treat tinnitus itself.

\section{References}

An YH, Jin SY, Yoon SW, Shim HJ (2014) The effects of unilateral tinnitus on auditory temporal resolution: gaps-in-noise performance. Korean J Audiol 18:119-125. 
Andersson G, Eriksson J, Lundh LG, Lyttkens L (2000) Tinnitus and cognitive interference: a stroop paradigm study. J Speech Lang Hear Res 43:1168-1173.

Araneda R, De Volder AG, Deggouj N, Philippot P, Heeren A, Lacroix E, Decat M, Rombaux P, Renier L (2015) Altered top-down cognitive control and auditory processing in tinnitus: evidences from auditory and visual spatial stroop. Restor Neurol Neurosci 33:67-80.

Axelsson A, Ringdahl A (1989) Tinnitus-a study of its prevalence and characteristics. Br J Audiol 23:53-62.

Bacon SP, Takahashi GA (1992) Overshoot in normal-hearing and hearingimpaired subjects. J Acoust Soc Am 91:2865-2871.

Baguley DM, McFerran D, Hall DA (2013) Tinnitus. Lancet 382:1600-1607.

Bellis TJ, Billiet C, Ross J (2008) Hemispheric lateralization of bilaterally presented homologous visual and auditory stimuli in normal adults, normal children, and children with central auditory dysfunction. Brain Cogn 66:280-289.

Bernstein LR, Trahiotis C (2016) Behavioral manifestations of audiometrically-defined "slight" or "hidden" hearing loss revealed by measures of binaural detection. J Acoust Soc Am 140:3540-3548.

Boyen K, Baş kent D, van Dijk P (2015) The gap detection test: can it be used to diagnose tinnitus? Ear Hear 36:e138-e145.

Brozoski T, Wisner K, Randall M, Caspary D (2019) Chronic sound-induced tinnitus and auditory attention in animals. Neuroscience 407:200-212.

Buzo BC, Carvallo RM (2014) Psychoacoustic analyses of cochlear mechanisms in tinnitus patients with normal auditory thresholds. Int J Audiol 53:40-47.

Campolo J, Lobarinas E, Salvi R (2013) Does tinnitus "fill in" the silent gaps? Noise Health 15:398-405.

Carlyon RP, Moore BCJ (1984) Intensity discrimination: a severe departure from Weber's law. J Acoust Soc Am 76:1369-1376.

Chen YC, Li X, Liu L, Wang J, Lu CQ, Yang M, Jiao Y, Zang FC, Radziwon K, Chen GD, Sun W, Krishnan Muthaiah VP, Salvi R, Teng GJ (2015) Tinnitus and hyperacusis involve hyperactivity and enhanced connectivity in auditory-limbic-arousal-cerebellar network. Elife 4:e06576.

Cohen J (1969) Statistical power analysis for the behavioral sciences. New York: Academic.

Cox RM, Matesich JS, Moore JN (1988) Distribution of short-term rms levels in conversational speech. J Acoust Soc Am 84:1100-1104.

Dornhoffer J, Danner C, Mennemeier M, Blake D, Garcia-Rill E (2006) Arousal and attention deficits in patients with tinnitus. Int Tinnitus J 12:9-16.

Dupuis K, Pichora-Fuller MK, Chasteen AL, Marchuk V, Singh G, Smith SL (2015) Effects of hearing and vision impairments on the Montreal cognitive assessment. Neuropsychol Dev Cogn B Aging Neuropsychol Cogn 22:413-437.

Epp B, Hots J, Verhey JL, Schaette R (2012) Increased intensity discrimination thresholds in tinnitus subjects with a normal audiogram. J Acoust Soc Am 132:EL196-201.

Feldmann H (1971) Homolateral and contralateral masking of tinnitus by noise-bands and by pure tones. Audiology 10:138-144.

Fournier P, Hébert S (2013) Gap detection deficits in humans with tinnitus as assessed with the acoustic startle paradigm: does tinnitus fill in the gap? Hear Res 295:16-23.

Furman AC, Kujawa SG, Liberman MC (2013) Noise-induced cochlear neuropathy is selective for fibers with low spontaneous rates. J Neurophysiol 110:577-586.

Gilles A, Schlee W, Rabau S, Wouters K, Fransen E, Van de Heyning P (2016) Decreased speech-in-noise understanding in young adults with tinnitus. Front Neurosci 10:288

Goodwin PE, Johnson RM (1980) The loudness of tinnitus. Acta Otolaryngol 90:353-359.

Hallam RS, McKenna L, Shurlock L (2004) Tinnitus impairs cognitive efficiency. Int J Audiol 43:218-226.

Henry JA, Dennis KC, Schechter MA (2005) General review of tinnitus: prevalence, mechanisms, effects, and management. J Speech Lang Hear Res 48:1204-1235

Husain FT, Akrofi K, Carpenter-Thompson JR, Schmidt SA (2015) Alterations to the attention system in adults with tinnitus are modality specific. Brain Res 1620:81-97.

Ibraheem OA, Hassaan MR (2017) Psychoacoustic characteristics of tinnitus versus temporal resolution in subjects with normal hearing sensitivity. Int Arch Otorhinolaryngol 21:144-150.
Ivansic D, Guntinas-Lichius O, Müller B, Volk GF, Schneider G, Dobel C (2017) Impairments of speech comprehension in patients with tinnitusa review. Front Aging Neurosci 9:224.

Jacobson GP, Calder JA, Newman CW, Peterson EL, Wharton JA, Ahmad BK (1996) Electrophysiological indices of selective auditory attention in subjects with and without tinnitus. Hear Res 97:66-74.

Jagoda L, Giroud N, Neff P, Kegel A, Kleinjung T, Meyer M (2018) Speech perception in tinnitus is related to individual distress level-a neurophysiological study. Hear Res 367:48-58.

Jain S, Dwarkanath VM (2016) Effect of tinnitus location on the psychoacoustic measures of hearing. Hearing Balance Commun 14:8-19.

Jain C, Sahoo JP (2014) The effect of tinnitus on some psychoacoustical abilities in individuals with normal hearing sensitivity. Int Tinnitus J 19:2835.

Jastreboff PJ (1990) Phantom auditory perception (tinnitus): mechanisms of generation and perception. Neurosci Res 8:221-254.

Jastreboff PJ, Jastreboff MM (2000) Tinnitus Retraining Therapy (TRT) as a method for treatment of tinnitus and hyperacusis patients. J Am Acad Audiol 11:162-177.

Jones PR, Moore DR, Amitay S, Shub DE (2013) Reduction of internal noise in auditory perceptual learning. J Acoust Soc Am 133:970-981.

Kaltenbach JA (2006) The dorsal cochlear nucleus as a participant in the auditory, attentional and emotional components of tinnitus. Hear Res 216217:224-234.

Leek MR, Brown ME, Dorman MF (1991) Informational masking and auditory attention. Percept Psychophys 50:205-214.

Léger AC, Moore BCJ, Lorenzi C (2012) Abnormal speech processing in frequency regions where absolute thresholds are normal for listeners with high-frequency hearing loss. Hear Res 294:95-103.

Li Z, Gu R, Zeng X, Qi M, Cen J, Zhang S, Gu J, Chen Q (2018) Eyes and ears: cross-modal interference of tinnitus on visual processing. Front Psychol 9:1779.

Luce RD, Green DM (1978) Two tests of a neural attention hypothesis for auditory psychophysics. Percept Psychophys 23:363-371.

McCormack A, Edmondson-Jones M, Somerset S, Hall DA (2016) A systematic review of the reporting of tinnitus prevalence and severity. Hear Res 337:70-79.

Mehdizade Gilani V, Ruzbahani M, Mahdi P, Amali A, Nilforush Khoshk MH, Sameni J, Karimi Yazdi A, Emami H (2013) Temporal processing evaluation in tinnitus patients: results on analysis of gap in noise and duration pattern test. Iran J Otorhinolaryngol 25:221-226.

Meikle M, Taylor-Walsh E (1984) Characteristics of tinnitus and related observations in over 1800 tinnitus clinic patients. J Laryngol Otol Suppl 9:17-21.

Meikle MB, Henry JA, Griest SE, Stewart BJ, Abrams HB, McArdle R, Myers PJ, Newman CW, Sandridge S, Turk DC, Folmer RL, Frederick EJ, House JW, Jacobson GP, Kinney SE, Martin WH, Nagler SM, Reich GE, Searchfield G, Sweetow R, et al. (2012) The tinnitus functional index: development of a new clinical measure for chronic, intrusive tinnitus. Ear Hear 33:153-176.

Mohamad N, Hoare DJ, Hall DA (2016) The consequences of tinnitus and tinnitus severity on cognition: a review of the behavioural evidence. Hear Res 332:199-209.

Möhrle D, Hofmeier B, Amend M, Wolpert S, Ni K, Bing D, Klose U, Pichler B, Knipper M, Rüttiger L (2019) Enhanced central neural gain compensates acoustic trauma-induced cochlear impairment, but unlikely correlates with tinnitus and hyperacusis. Neuroscience 407:146-169.

Moon IJ, Won JH, Kang HW, Kim DH, An YH, Shim HJ (2015) Influence of tinnitus on auditory spectral and temporal resolution and speech perception in tinnitus patients. J Neurosci 35:14260-14269.

Moore BCJ (1996) Perceptual consequences of cochlear hearing loss and their implications for the design of hearing aids. Ear Hear 17:133-161.

Moore BCJ (2012) The psychophysics of tinnitus. In: Tinnitus: Springer handbook of auditory research (Eggermont JJ, Zeng FG, Popper AR, Fay RR, eds), pp 187-216. New York: Springer.

Moore BCJ, Peters RW (1992) Pitch discrimination and phase sensitivity in young and elderly subjects and its relationship to frequency selectivity. J Acoust Soc Am 91:2881-2893.

Moore BCJ, Vinay (2010) The relationship between tinnitus pitch and the edge frequency of the audiogram in individuals with hearing impairment and tonal tinnitus. Hear Res 261:51-56. 
Moore BCJ, Huss M, Vickers DA, Glasberg BR, Alcántara JI (2000) A test for the diagnosis of dead regions in the cochlea. Br J Audiol 34:205-224.

Morse K, Vander Werff KR (2019) Comparison of silent gap in noise cortical auditory evoked potentials in matched tinnitus and no-tinnitus control subjects. Am J Audiol 28:260-273.

Muhlnickel W, Elbert T, Taub E, Flor H (1998) Reorganization of auditory cortex in tinnitus. Proc Natl Acad Sci U S A 95:10340-10343.

Newman CW, Jacobson GP, Spitzer JB (1996) Development of the tinnitus handicap inventory. Arch Otolaryngol Head Neck Surg 122:143-148.

Norena A, Micheyl C, Chéry-Croze S, Collet L (2002) Psychoacoustic characterization of the tinnitus spectrum: implications for the underlying mechanisms of tinnitus. Audiol Neurootol 7:358-369.

Okamoto H, Stracke H, Stoll W, Pantev C (2010) Listening to tailor-made notched music reduces tinnitus loudness and tinnitus-related auditory cortex activity. Proc Natl Acad Sci U S A 107:1207-1210.

Pan T, Tyler RS, Ji H, Coelho C, Gehringer AK, Gogel SA (2009) The relationship between tinnitus pitch and the audiogram. Int J Audiol 48:277294.

Patuzzi RB, Brown DJ, McMahon CM, Halliday AF (2004) Determinants of the spectrum of the neural electrical activity at the round window: transmitter release and neural depolarisation. Hear Res 190:87-108.

Paul BT, Bruce IC, Roberts LE (2017) Evidence that hidden hearing loss underlies amplitude modulation encoding deficits in individuals with and without tinnitus. Hear Res 344:170-182.

Penner MJ (1987) Masking of tinnitus and central masking. J Speech Hear Res 30:147-152.

Penner MJ (1995) Tinnitus synthesis: fluctuant and stable matches to the pitch of tinnitus. Int Tinnitus J 1:79-83.

Reavis KM, Rothholtz VS, Tang Q, Carroll JA, Djalilian H, Zeng FG (2012) Temporary suppression of tinnitus by modulated sounds. J Assoc Res Otolaryngol 13:561-571.

Reed GF (1960) An audiometric study of two hundred cases of subjective tinnitus. AMA Arch Otolaryngol 71:84-94.

Reynolds JH, Heeger DJ (2009) The normalization model of attention. Neuron 61:168-185.

Roberts LE, Eggermont JJ, Caspary DM, Shore SE, Melcher JR, Kaltenbach JA (2010) Ringing ears: the neuroscience of tinnitus. J Neurosci 30:14972-14979.

Roberts LE, Husain FT, Eggermont JJ (2013) Role of attention in the generation and modulation of tinnitus. Neurosci Biobehav Rev 37:1754-1773.

Rossiter S, Stevens C, Walker G (2006) Tinnitus and its effect on working memory and attention. J Speech Lang Hear Res 49:150-160.

Sanches SG, Sanchez TG, Carvallo RM (2010) Influence of cochlear function on auditory temporal resolution in tinnitus patients. Audiol Neurootol 15:273-281.

Schlauch RS (1992) A cognitive influence on the loudness of tones that change continuously in level. J Acoust Soc Am 92:758-765.

Sedley W, Friston KJ, Gander PE, Kumar S, Griffiths TD (2016) An integrative tinnitus model based on sensory precision. Trends Neurosci 39:799812 .

Shailer MJ, Moore BCJ (1987) Gap detection and the auditory filter: phase effects using sinusoidal stimuli. J Acoust Soc Am 81:1110-1117.

Shore SE, Wu C (2019) Mechanisms of noise-induced tinnitus: insights from cellular studies. Neuron 103:8-20.

Soalheiro M, Rocha L, do Vale DF, Fontes V, Valente D, Teixeira LR (2012) Speech recognition index of workers with tinnitus exposed to environmental or occupational noise: a comparative study. J Occup Med Toxicol 7:26.

Starr A, Picton TW, Sininger Y, Hood LJ, Berlin CI (1996) Auditory neuropathy. Brain 119:741-753.

Stevens C, Walker G, Boyer M, Gallagher M (2007) Severe tinnitus and its effect on selective and divided attention. Int J Audiol 46:208-216.

Stouffer JL, Tyler RS (1990) Characterization of tinnitus by tinnitus patients. J Speech Hear Disord 55:439-453.

Studebaker GA, Pavlovic CV, Sherbecoe RL (1987) A frequency importance function for continuous discourse. J Acoust Soc Am 81:1130-1138.

Tai Y, Husain FT (2018) Right-ear advantage for speech-in-noise recognition in patients with nonlateralized tinnitus and normal hearing sensitivity. J Assoc Res Otolaryngol 19:211-221.

Tai Y, Husain FT (2019) The role of cognitive control in tinnitus and its relation to speech-in-noise performance. J Audiol Otol 23:1-7.

Tan CM, Lecluyse W, McFerran D, Meddis R (2013) Tinnitus and patterns of hearing loss. J Assoc Res Otolaryngol 14:275-282.

Turner JG, Brozoski TJ, Bauer CA, Parrish JL, Myers K, Hughes LF, Caspary DM (2006) Gap detection deficits in rats with tinnitus: a potential novel screening tool. Behav Neurosci 120:188-195.

Tyler RS, Baker LJ (1983) Difficulties experienced by tinnitus sufferers. J Speech Hear Disord 48:150-154.

Vernon JA, Meikle MB (1981) Tinnitus masking: unresolved problems. Ciba Found Symp 85:239-262.

Vielsmeier V, Kreuzer PM, Haubner F, Steffens T, Semmler PR, Kleinjung T, Schlee W, Langguth B, Schecklmann M (2016) Speech comprehension difficulties in chronic tinnitus and its relation to hyperacusis. Front Aging Neurosci 8:293

Viemeister NF (1979) Temporal modulation transfer functions based upon modulation thresholds. J Acoust Soc Am 66:1364-1380.

Weisz N, Hartmann T, Dohrmann K, Schlee W, Norena A (2006) High-frequency tinnitus without hearing loss does not mean absence of deafferentation. Hear Res 222:108-114.

Yang S, Weiner BD, Zhang LS, Cho SJ, Bao S (2011) Homeostatic plasticity drives tinnitus perception in an animal model. Proc Natl Acad Sci U S A 108:14974-14979.

Zeng FG (2013) An active loudness model suggesting tinnitus as increased central noise and hyperacusis as increased nonlinear gain. Hear Res 295:172-179.

Zeng FG, Liu S (2006) Speech perception in individuals with auditory neuropathy. J Speech Lang Hear Res 49:367-380.

Zeng FG, Chen H, Han S (2005a) Temporal masking in electric hearing. J Assoc Res Otolaryngol 6:390-400.

Zeng FG, Kong YY, Michalewski HJ, Starr A (2005b) Perceptual consequences of disrupted auditory nerve activity. J Neurophysiol 93:3050-3063.

Zeng FG, Nie K, Stickney GS, Kong YY, Vongphoe M, Bhargave A, Wei C, Cao K (2005c) Speech recognition with amplitude and frequency modulations. Proc Natl Acad Sci U S A 102:2293-2298.

Zeng FG, Tang Q, Dimitrijevic A, Starr A, Larky J, Blevins NH (2011) Tinnitus suppression by low-rate electric stimulation and its electrophysiological mechanisms. Hear Res 277:61-66.

Zhang GW, Sun WJ, Zingg B, Shen L, He J, Xiong Y, Tao HW, Zhang LI (2018) A non-canonical reticular-limbic central auditory pathway via medial septum contributes to fear conditioning. Neuron 97:406-417.e4.

Zwicker E (1965) Temporal effects in simultaneous masking and loudness. J Acoust Soc Am 38:132-141. 